\title{
La función de la crítica en la filosofía jurídica latinoamericana*
}

ANTONIO CARLOS WOLKMER**

\section{Introducción}

Uno de los mayores desafíos de las últimas décadas es cómo participar del contexto social de la globalización mundial en desarrollo, pero sin dejar de estar integrado y actuar activamente en el plano cultural de la legitimidad local. Se trata de construir un proyecto social y político que sea capaz de emancipar y reordenar las relaciones tradicionales entre Estado y sociedad civil, entre el universalismo ético y el relativismo cultural, entre la razón práctica y la filosofía del sujeto, entre las formas convencionales de legalidad y las experiencias noformales de jurisdicción.

Reinscribir un nuevo modo de vida estimula la inserción cultural en otras modalidades de convivencia, de relaciones sociales y reglamentaciones de las prácticas emergentes e instituidas. En tal esce- nario, el énfasis no estará en el Estado y en el mercado, pero sí ahora en la sociedad civil como nuevo espacio público que haga efectiva la pluralidad democrática. En su capacidad generadora, la nueva esfera pública proporciona, para los horizontes institucionales, nuevos valores culturales, nuevos procedimientos de práctica política y de acceso a la justicia, proyectando nuevos actores sociales como fuente de legitimación del espacio social y de la constitución emergente de los derechos.

Así, desde ahí, delante del surgimiento de nuevas formas de dominación y de exclusión producidas por la globalización y por el neoliberalismo que afectaron sustancialmente prácticas sociales, formas de representación y de legitimación, se impone repensar el poder comunitario, el retorno de los sujetos históricos y la producción alternativa de juridicidad a través de la pluralidad de fuentes. Evi-

\footnotetext{
Artículo publicado con autorización de su autor.

** El autor es Profesor titular de los cursos de Graduación y Posgrado en Derecho de la UFSC (Brasil). Doctor en Filosofía del Derecho y de Política. Socio pleno del Instituto de Abogados Brasileños (RJ). Investigador del CNPq y de la Fondazione Cassamarca (Treviso, Italia). Profesor visitante de varias universidades brasileñas y de la Universidad Pablo de Olavide (Sevilla-España). Autor de diversos libros, entre otros: Direito e justiça na américa indígena: da conquista à colonização. Porto Alegre: Livraria do Advogado, 1998; Pluralismo jurídico - Fundamentos de uma nova cultura no direito. 3 ed. São Paulo: Alfa-Omega, 2001; História do direito no Brasil. 3 ed. Rio de Janeiro: Forense, 2002; Introdução ao pensamento jurídico crítico. 4 ed. São Paulo: Saraiva, 2002; Direitos humanos e filosofia jurídica na América Latina. Rio de Janeiro: Lumen Juris, 2003.
} 
dentemente la constitución de una cultura jurídica pluralista fundada en los valores del poder comunitario está necesariamente vinculada a los criterios de una nueva legitimidad. El nivel de esa eficacia pasa por la legitimidad de los actores sociales involucrados y de sus necesidades y reivindicaciones. Por consiguiente, es fundamental destacar, en la presente contemporaneidad del derecho, las nuevas formas plurales y alternativas de legitimación del derecho.

Antes que nada, para que se constituya una cultura jurídica pluralista, alternativa y democrática, es necesario, primero, reflexionar y forjar un pensamiento crítico, construido a partir de la praxis de las sociedades emergentes, capaz de viabilizar nuevos conceptos, categorías, representaciones e instituciones sociales.

\section{El pensamiento crítico como base de la emancipación en el contexto histórico latinoamericano}

Importa, ahora, avanzar en la delimitación de un instrumental teórico capaz de expresar y sustentar todo discurso acerca de una práctica pluralista y alternativa del Derecho en la perspectiva de América Latina.

Inicialmente, es necesario señalar los diversos sentidos emanados de la expresión "crítica", término que no deja de ser ambiguo y amplio, pues representa innumerables significados, siendo interpretado y utilizado de diversas formas en el espacio y en el tiempo. De cualquier modo, la "crítica" surge como elaboración instrumental dinámica que sobrepasa los límites naturales de las teorías tradicionales, no ajustándose apenas a describir lo que está establecido o a contemplar, de un modo equidistante, los fenómenos sociales y reales ${ }^{1}$. Se reconoce, también, que la "crítica" puede revelar y esclarecer lo dicho por Paulo Freire,

(...) aquel conocimiento que no es dogmático, ni permanente, pero que existe en un continuo proceso de hacerse a sí mismo. $Y$, siguiendo la posición de que no existe conocimiento sin praxis, el conocimiento 'crítico' sería aquel relacionado con un cierto tipo de acción que resulta de la transformación de la realidad. Solamente una teoría 'crítica' puede ser el resultado de liberación del ser humano, pues no existe transformación de la realidad sin la liberación del ser humano².

Como proceso histórico identificado con lo utópico, lo radical y lo desmitificador, la "crítica" asume la "función de abrir alternativas de acción y margen de posibilidades que se proyectan sobre las

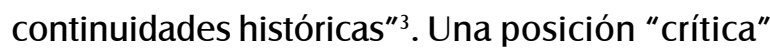
tiene que ser vista, por consiguiente, no sólo como una evaluación crítica "de nuestra condición presente, pero sí en dirección a una nueva existencia $(. . .)^{\prime 4}$.

Entendiendo la crítica como instrumental pedagógico de ruptura y de liberación, la cuestión que se presenta a continuación es cómo viabilizarla en la inserción de la trayectoria de la sociedad y de la cultura latinoamericana. Aunque engendrado históricamente por discontinuidades y flujos deterministas alienígenos, se puede creer en la existencia de un pensamiento latinoamericano.

En realidad, el pensamiento latinoamericano contenido, explícita o implícitamente, en la produc-

1 Cf. WOLKMER, Antonio Carlos. "Matrizes teóricas para se repensar uma crítica no direito". "En: Revista do Instituto de Pesquisas e Estudos. Bauru: ITE, n. 25, abr./jul. 1999. p. 102.

2 FREIRE, Paulo. In: WOLKMER, Antonio Carlos. Introdução ao pensamento jurídico crítico. 4 ed. São Paulo: Saraiva, 2002. p. 3-4.

3 HABERMAS, Jürgen. In: SANTIAGO, Gabriel L. As utopias latino-americanas: em busca de uma educação libertadora. Campinas: Alínea, 1988. p. 44.

4 QUINNEY, Richard. In: WOLKMER, Antonio Carlos. Ideologia, estado e direito. 3 ed. São Paulo: Revista dos Tribunais, 2000. p. 5. 
ción cultural de sus autores, escritores y filósofos, refuerza la premisa de que lo importante "(...) no es intentar afirmar tal pensamiento como verdad o como aquel más adecuado a la región, sino al contrario, un pensamiento como $(. . .)^{\prime \prime 5}$ manifestación apto para instrumentalizar la fuerza de su crítica en el sentido de contribuir en la des-construcción de las viejas prácticas de saber y de poder dominantes.

En efecto, la edificación de un pensamiento crítico latinoamericano no implica la total negación o la ruptura radical con otras formas racionales de conocimiento heredadas del iluminismo y producidas por la modernidad europea o norteamericana, pero sí un proceso dialéctico de asimilación, transposición y reinvención. Se trata de ir concretando, como dice el filósofo peruano Augusto Salazar Bondy, una práctica cultural crítica en la cual se irá reformulando la realidad histórica; es el trabajo de recreación en la dirección emergente para el nuevo proyecto de emancipación, síntoma genuino y auténtico de un pensamiento crítico orientado políticamente para la desalienación y para la liberación ${ }^{6}$.

Como ya se advirtió en otro momento ${ }^{7}$. una teoría o pensamiento de perspectiva crítica opera en la búsqueda de liberar al hombre de su condición de alienado, de su reconciliación con la naturaleza norepresora y con el proceso histórico por él formado. La "crítica", como saber y práctica de la liberación, tiene que demostrar hasta qué punto los individuos están cosificados y formados por los determinismos históricos, pero no siempre están concientes de las implicancias hegemónicas, de las opresiones disimuladas y de las falacias ilusorias del mundo objetivo/real. El pensamiento crítico tie- ne la función de provocar la autoconciencia de los sujetos sociales oprimidos que sufren las injusticias por parte de los sectores dominantes de los grupos privilegiados y de las formas institucionalizadas de violencia y de poder (local o global). Sin dudas, la "crítica" como dimensión epistemológica e ideológica tiene un papel pedagógico altamente positivo, a medida que se transforma como instrumental operante adecuado al esclarecimiento, resistencia y emancipación, yendo al encuentro y respondiendo a las ansias, intereses y necesidades de todos aquellos que sufren cualquier forma de discriminación, explotación y exclusión.

De igual modo, para constituir una nueva cultura de la alteridad y de la pluralidad, a través de ciertas categorías críticas emergentes en la perspectiva latinoamericana, ya sea como forma de destrucción de la dominación, ya sea como instrumento pedagógico de la liberación, abarca dos condiciones esenciales:

1) Se inspira en la "praxis concreta" y en la situación histórica de las estructuras socioeconómicas de América Latina, secularmente explotadas, dependientes, marginadas y colonizadas;

2) Las categorías teóricas y los procesos de conocimiento se encuentran en las propias culturas teológica, filosófica y socio-política latinoamericanas $^{8}$. En este sentido, cabe aprehender los substratos fomentadores de un pensamiento con identidad propia y de vanguardia, provenientes tanto de la Teología (Gustavo Gutiérrez, Hugo Assmann, Clodovis y Leonardo Boff) y de la Filosofía (Enrique D. Dussel, Augusto Salazar Bondy, Leopoldo Zea, Alejandro Serrano Calde-

5 SANTIAGO, Gabriel L. Op. cit., p. 27.

6 SALAZAR BONDY, Augusto. ¿Existe una filosofía de nuestra América? 8 ed. México: Siglo Veintiuno, 1982. Igualmente: ZEA, Leopoldo. La filosofía americana como filosofía sin más. 3 ed. México: Siglo Veintiuno, 1975; __ . El pensamiento latinoamericano. 3 ed. Barcelona: Ariel, 1976, p. 526.

7 Cf. WOLKMER, Antonio Carlos. “Matrizes teóricas para se repensar uma crítica no direito”., pp. 102-103. también ver: Introdução ao pensamento jurídico crítico. pp. 9-11.

8 Extratos de idéias escolhidos de: Pluralismo jurídico - Fundamentos de uma nova cultura no direito., pp. 268-269. 
ra, Raul Fornet-Betancourt) como de la Economía (Rui Marini, Theotônio dos Santos, Celso Furtado, Franz J. Hinkelammert), de la Geografía (Milton Santos), de la Pedagogía (Paulo Freire), de la Sociología (Fals Borda), de la Antropología (Darcy Ribeiro), de la Política (José Martí, José Carlos Mariátegui) y del Derecho (Jesús A. de la Torre Rangel, David Sánchez Rubio).

\section{La inserción de la crítica en la producción de la filosofía de la política y del derecho}

Teniendo en cuenta los conceptos de "crítica", como expresión del conocimiento radical desmitificador y como transposición de lo instituido opresor, se pasa, ahora, a la clara conexión con lo que sea política y derecho como instrumentales de la práctica alternativa emancipadora. En concreto, el "criterio" base de toda filosofía crítica de la política y del derecho será expresar la defensa de los principios básicos de la vida humana digna, y de la libertad y de la justicia9.

Es en esta perspectiva que una filosofía política crítica asume la responsabilidad de instrumentalizar la razón de ser y la fundamentación para combatir lo que Enrique Dussel designa como "la no-verdad, la no-validez (deslegitimación), la no-eficacia de la decisión, de la norma, de la ley, de la acción, de la institución o del orden político vigente e injusto desde la perspectiva específica de la víctima, del excluido"10. Así, la filosofía política crítica revela un diagnóstico correcto y una praxis transformadora de las patologías de lo instituido y de las diversas formas de la "negatividad material" (miseria, marginalización, exclusión, negación de la ciuda- danía). El punto de partida de la filosofía política crítica es la "negatividad material", factor determinante para que el orden político vigente imposibilite la "reproducción de la vida" y la "participación" legítima y democrática de los "oprimidos del proceso de globalización, de las clases explotadas, de las poblaciones autóctonas excluidas, de los marginales, de los inmigrantes pobres y tantos otros grupos sociales afectados (...)"11 . La política crítica debe, también comprometerse con los "actores sociales diferenciados y excluidos", buscar "organizar los movimientos sociales necesarios" y contribuir para edificar "positivamente alternativas a los sistemas político, jurídico, económico, ecológico y educativo vigentes $(. . .)^{\prime \prime 2}$. La verdadera filosofía política crítica, que sobrepasa el nihilismo e individualismo crítico post-modernista, pautado, según Dussel, por estrategias crítico-emancipadoras, desencadenando luchas en diferentes "'frentes de liberación' (de los excluidos, pobres, razas discriminadas, sexos oprimidos, viejos abandonados, niños explotados, pueblos ignorados, culturas exterminadas, etnias menospreciadas)" y afirmando el desarrollo de la vida y de la libertad humanas en su dimensión universal. En suma, la filosofía crítica de la política debe actuar asumiendo la responsabilidad por la dignidad del otro y contribuyendo para implementar estructuras políticas justas y legítimas, mediante "nuevas normas, leyes, acciones e instituciones políticas"13.

De igual modo, como se puede proyectar una nueva filosofía política, no menos relevante es extender la problemática a una juridicidad crítica de perspectiva pluralista.

Resulta, también, imprescindible tener como punto de partida para cualquier reflexión sobre dere-

9 Cf. SANCHEZ RUBIO, David. Filosofía, derecho y liberación en América Latina. Bilbao: Desclée de Brouwer, 2000, pp. 180-183.

10 DUSSEL, Enrique. Hacia una filosofía política crítica. Bilbao: Desclée de Brouwer, 2001, p. 54.

11 DUSSEL, Enrique. Op. cit., pp. 58-59.

12 DUSSEL, Enrique. Op. cit., p. 60.

13 DUSSEL, Enrique. Op. cit., p. 64. 
cho y justicia la inclusión del paradigma de la "vida humana" con dignidad. En la perspectiva de las premisas orientadoras de la ética de la alteridad, Enrique Dussel advierte lo imperativo de la vida humana para la construcción de una realidad social justa, que restaure "(...) la dignidad negada de la vida de la víctima, del oprimido o del excluido"14. Esta perspectiva de la alteridad que prioriza al ser humano concreto, se manifiesta en la fundamentación crítica de otra juridicidad y en la condición real de emergencia de nuevos derechos esenciales. De este modo, frente a los grandes paradigmas de la tradición occidental (ser, conocer y comunicación) ${ }^{15}$. Dussel presenta, en la transposición de la totalidad excluyente y en la dimensión, ahora, de la exterioridad liberadora, elementos críticos de una ética centrada en el "Otro", base para repensar la cuestión de la justicia y de los derechos humanos.

Así, el concepto de liberación, tomado de la ética de la alteridad de Dussel, ha favorecido el surgimiento de un análisis crítico de la juridicidad formalista y opresora por parte de los jusfilósofos como Jesús Antonio de la Torre Rangel (México) y David Sánchez Rubio (España).

Hay que considerar, como afirma Jesús A. de la Torre Rangel, que el derecho tiene su raíz en el ser humano. Sin dudas, "es el Otro, desde la exterioridad, el que dará siempre la pauta de una búsqueda histórica de la vigencia real de los derechos humanos, de la justicia y del bien común"16. Pero en particular, según De La Torre Rangel, la juridicidad moderna, por ser alienante, será sobrepasada por un pensamiento crítico-filosófico que tome en cuenta la
(...) lucha del pueblo por justicia, cuando el otro sea reconocido como otro. El primer momento será reconocer la desigualdad de los desiguales, y a partir de allí vendrá el reconocimiento pleno no ya del desigual, pero sí del distinto portador de la justicia como otro. El Derecho perderá su generalidad, su abstracción y su impersonalidad. Y el rastro del otro como clase alienada que provoca la justicia (...). Por esta razón, (...) la búsqueda de justicia concreta rompe con todo un aparato jurídico que sólo existe para mantener el lucro y el poder ${ }^{17}$.

En otra juridicidad crítica que parte de los aportes de Dussel y Hinkelammert, David Sánchez Rubio muestra, también, que la liberación se legitima como la expresión de lucha de los excluidos por sus derechos. Al relacionar liberación con justicia y derechos humanos, el profesor de la Universidad de Sevilla deja claro que, "(...) hablar de liberación es apostar por una determinada concepción de justicia cuya opción son los pobres y que, en el contexto actual, se manifiesta (...) con las víctimas del sistema social capitalista"18. Esto explica la razón del concepto de justicia y cómo pasa a ser tan importante en América Latina. Precisando todavía más, puntualiza Sánchez Rubio que en la justicia reclamada por los colectivos marginalizados y por los pobres excluidos de sus derechos se revela la fuente más auténtica "(...) de toda lucha contra situaciones de explotación. El Derecho a la vida y el Derecho a la libertad, entendidos en un sentido tanto individual como colectivo, forman el espacio mínimo a partir del cual la dignidad humana se desarroIla en los contextos de adversidad, miseria y dominación"19.

\footnotetext{
14 DUSSEL, Enrique. Ética da libertação. Na idade da globalização e da exclusão. Petrópolis: Vozes, 2000, p. 93.

15 Ver: AZEVEDO, Mônica Louise de. “Direito humanos e filosofia da libertação". En: Revista Argumenta. Jacarezinho: Fundinopi, 2001, pp. 184-185.

16 DE LA TORRE RANGEL, Jesus Antonio. Derechos humanos desde el jusnaturalismo histórico analógico. Mexico: Porrúa/UAA, 2001, p. 100.

17 RANGEL, Jesus Antonio de la Torre. El derecho que nace del pueblo. Aguascalientes: CIRA, 1986, p. 56.

18 SANCHEZ RUBIO, David. Op Cit., p. 178.

19 Ibíd., pp. 157 y 180.
} 
Por lo tanto, el pensamiento crítico, forjado en la denuncia y en la lucha de los propios oprimidos contra las falsas legitimidades y las falacias opresoras del formalismo legalista de la modernidad, sirve de substrato para una auténtica y genuina filosofía jurídica de la alteridad. Reconoce Dean F. B. de Almeida que, al contribuir para superar el formalismo juspositivista, la propuesta de la alteridad jurídica latinoamericana “(...) representa una nueva postura práctico-reflexiva (...) rompiendo con la hegemonía del pilar de regulación y con el mito de la modernidad norteamericana" ${ }^{20}$.

En estas condiciones norteadas por una filosofía jurídica crítico-emancipadora, las prácticas plurales de juridicidad se evaden del individualismo sistémico de dominación para transformarse en instrumento responsable por el cambio social. Esa fiIosofía jurídica de la alteridad, incorporando las necesidades fundamentales (libertad, justicia, vida digna y derechos humanos) de nuevos actores históricos, posibilita el verdadero descubrimiento de un sujeto social emergente, un derecho que revela y legitima por sobre todo la dignidad del Otro, que lo respeta y lo protege. El derecho orientado para la liberación deja de legitimar y asegurar el interés de los sectores sociales dominantes “(...) para transformarse en el instrumento vivo de humanización de la sociedad latinoamericana (...)"2121.

En síntesis, la crítica permite una consideración histórica para reconocer una nueva cultura jurídica marcada por el pluralismo comunitario-participativo y por la legitimidad construida a través de las prácticas internalizadas por nuevos sujetos sociales.

\section{Formas plurales y alternativas de le- gitimación del derecho}

En la crisis del proyecto cultural de la modernidad occidental, se constata la transposición de modelos de fundamentación y de desarrollo para nuevos parámetros científicos de conocimiento. Los modelos de referencia político y jurídico de corte racionalista, individualista y universal están siendo radicalmente debatidos en lo que atañe a sus conceptos, sus fuentes y sus institutos frente a la pluralidad de transformaciones técnico-científicas, de las experiencias de vida diferenciadas, de la complejidad creciente de bienes valorados y de necesidades básicas, así como de la emergencia de actores sociales portadores de nuevas subjetividades (individuales y colectivas). Además, las necesidades, los conflictos y los nuevos problemas producidos por la sociedad en el inicio del milenio generan también formas alternativas de legitimación de derechos que desafían y dificultan la teoría clásica del Derecho $^{22}$.

Así, los presupuestos sustantivos que constituyen y sustentan nuevas formas de legitimación, requieren de la justicia, requieren del derecho, deben ser buscados en la acción participativa de los sujetos sociales emergentes y en la justa satisfacción de sus necesidades fundamentales.

En primer lugar, cabe considerar que en el espacio de la "pluralidad de interacciones de las formas de vida, emplear procesos comunitarios significa adoptar estrategias de acción vinculadas a la participación consciente y activa de nuevos sujetos socia-

20 BUENO DE ALMEIDA, Dean Fabio. América Latina: filosofia jurídica da alteridade. Curitiba, 2002, p. 24. Mimeo.

21 Ibíd., p. 25.

22 Cf. WOLKMER, Antonio Carlos. "Introdução aos fundamentos de uma teoria geral dos novos direitos". 2001, pp. 2-3. [Mimeo.] 
les. Es ver en cada esencia humana (individual y colectiva) un ser capaz de actuar de forma solidaria y emancipadora, cediendo al inmovilismo pasivo y a los beneficios individualistas comprometidos $^{\prime 23}$.

Es de este modo que la reconsideración y la redimensionalidad del concepto histórico de "sujeto" está una vez más asociado a una tradición de utopías revolucionarias de luchas y resistencias. En la presente contemporaneidad, en un escenario de exclusiones, opresiones y carencias, las prácticas emancipadoras e insurgentes de las nuevas identidades sociales (múltiples grupos de intereses, movimientos sociales, cuerpos intermedios, redes de intermediación, ONGs) se revelan como portadoras potenciales de nuevas y legítimas formas de hacer política, así como fuente alternativa y plural de producción jurídica ${ }^{24}$.

La ineficacia de las instancias legislativas y jurisdiccionales del clásico Derecho Moderno favorecen "la expansión de procedimientos extrajudiciales y prácticas normativas no-estatales", ejercidas dialógicamente y consensualizadas por sujetos sociales que, a pesar de ser, a veces, oprimidos e "insertos en la condición de 'ilegalidad' para las diversas esferas del sistema oficial, definen una forma plural y emancipadora de legitimación. [...]. Los centros generadores de derecho ya no se reducen a las instituciones y a los órganos representativos del monopolio del Estado moderno, pues el derecho, por estar inserto en las prácticas y en las relaciones sociales de las cuales es fruto, emerge de diversos centros de producción normativa.
Las nuevas exigencias globalizadas y los conflictos en espacios sociales y políticos periféricos, tensos y desiguales, hacen, hoy, significativo reconocer, en la figura de los nuevos movimientos sociales, una fuente legítima para engendrar prácticas de justicia alternativa y derechos emergentes, así como viabilizar prácticas legitimadoras de resistencia al desenfrenado proceso de desreglamentación y desconstitucionalización de la vida ${ }^{25}$.

Puesta la tematización de los sujetos sociales, cabe considerar también la constitución de las necesidades humanas y su justa satisfacción como criterio para ser pensadas nuevas formas de legitimación en el ámbito de la juridicidad. La estructura de las necesidades humanas (existenciales, materiales y culturales) que permea la colectividad se refiere tanto a un proceso de subjetividad, modos de vida, deseos y valores, como a la constante "ausencia" o "vacío" de algo anhelado y no siempre realizable. Por ser inagotables e ilimitadas en el tiempo y en el espacio, las necesidades humanas están en permanente redefinición y creación ${ }^{26}$. El conjunto de las necesidades humanas varían de una sociedad o cultura a otra, abarcando un amplio y complejo proceso de socialización. Hay que distinguir, por lo tanto, en la problemática de las necesidades, sus implicaciones contingentes con exigencias de legitimación.

De esta forma, una necesidad "puede ser reconocida como legítima si su satisfacción no incluye la utilización de otra persona como mero medio" ${ }^{27}$. Se hace, de veras, condenable cualquier determinación arbitraria sobre la calidad y la cantidad de

\footnotetext{
23 Cf. WOLKMER, Antonio Carlos. "Direitos, poder local e novos sujeitos sociais". En: RODRÍGUES, H. W. [Org.]. O direito no terceiro milênio. Canoas: Ulbra, 2000, p. 97.

24 WOLKMER, “Direitos, poder...", Op. Cit., p. 104.

25 Cf. Ibíd., p. 104-105.

26 Cf. WOLKMER, Antonio Carlos. “Sobre a teoria das necessidades: a condição dos novos direitos". En: Alter Ágora. Florianópolis: CCJ/UFSC, n. 01, mayo/ 1994, p. 43.

27 HELLER, Agnes; FEHÉR, Ferenc. Políticas de la postmodernidad. Barcelona: Península, 1989, pp. 171-172. Ver también: HELLER, Agnes. Teoría de las necesidades en Marx. Barcelona: Península, 1978.
} 
las necesidades. Le cabe al ciudadano - comprometido con el procedimiento justo - no sólo rechazar la idea de objetivaciones cotidianas interiorizadas por la dominación, sino, sobretodo, "practicar el reconocimiento de todas las necesidades, cuya satisfacción no supone el uso" y la explotación de los demás miembros de la comunidad ${ }^{28}$. Es en esta perspectiva compartida que importa rescatar la presencia plural de los nuevos sujetos sociales que se transforman en fuentes de legitimación de una nueva forma de hacer efectiva la justicia y una nueva manera de constituir derechos ${ }^{29}$.

Así, la razón de ser de una juridicidad alternativa está en la trasgresión a lo convencional instituido e injusto, en la posibilidad de revelarse como instrumental de construcción de una sociedad más justa, edificada en valores nacidos de prácticas sociales emancipadoras.

En síntesis, los presupuestos de fundamentación de la producción de nuevos derechos y de múltiples experiencias de jurisdicción comunitaria están directamente asociados a la fuerza de la legitimidad de las subjetividades plurales recientes y al nivel de la justa satisfacción de las necesidades de la vida humana con dignidad. 